\title{
87
}

\section{Collaborative learning: teaching ethical theory in a computerized, case study format}

\author{
Patrick Kelly \\ Christopher G. Smith \\ Mark W. Bridges \\ Georgia Institute of Technology \\ Atlanta \\ USA
}

\begin{abstract}
A perennial issue in academia is how best to enable students to learn and retain course material. This challenge is especially acute with large classes which stretch instructional resources-an increasingly common situation. The authors developed and implemented a method which utilizes collaborative writing as an integral learning component of Georgia Tech's Ethical Theory course. An elaborate collaborative model for learning ethical theories by using them is incorporated into a computing tool called CALVIN. This computing system serves as a 'virtual' learning laboratory for the students outside the classroom.
\end{abstract}

Main conference themes: social issues

Educational areas: higher education

Study topics:

Secondary keywords: case studies, collaborative learning, distance learning 


\section{PROBLEM STATEMENT—SOLUTION SUMMARY}

Many students develop rather remarkable capacities to learn, in some sense of the word, course materials on which they are to be examined and to hold these materials in 'short term' memory until the exam event has passed. How much is thereafter 'saved' in their longer term memory where it is available for later use, is problematic. Having long observed and been frustrated by this 'exam memory' phenomenon the authors developed a multifaceted strategy for increasing the probability of getting materials into the student's long term memory. The common practice of encouraging student interaction in the classroom as a means of occasioning greater use of the course materials to facilitate long term recall, is foreclosed in this instance by the necessity of large classes (120 to 180 students). Within this constraint the elements of the strategy we have devised are:

- multimedia presentation of the ideas as a complement to the lecture format;

- case studies to which students must apply the ideas presented in the lectures and readings;

- a collaborative learning mode in which they must help their peers apply the ideas and, in turn, have others afford them such help;

- a substantial writing component to reinforce their thinking about the ideas presented in these several forms;

- the use of computers, both PC and mainframe, to tie these other elements together.

\section{An idea in waiting}

The core idea with which we began in early 1991, was to have students collaborate in applying the ethical theories they were studying to a set of moral dilemmas in the form of case studies. We thought of it as having them take the theories out for 'test drives' to get a sense of how it would be to make moral decisions from perspectives other than their own. The collaborators would not meet to do their work; it would be, if you will, 'distance learning' on the same campus, as each group's preliminary draft and subsequent critiques would be shared via a mainframe computer and the final reports posted there as well. The students would not exchange paper; the instructor would not accept it.

A sponsor's resources made possible the development of the software system named CALVIN. This system is detailed below, but first we need to describe the student tasks and their sequence as well as the course itself. 


\section{Overview of the collaborative, case study process}

The case studies are devices for 'road testing' the ethical theories students are learning in the text and lectures. They can 'get behind the wheel' and take these theories for a spin on the rough terrain of case studies chosen to highlight their strengths and weaknesses. The purpose is not necessarily to change, or even to challenge, how students conduct their moral business, but to give them a feel for how a wide range of other people conduct theirs. To this end there are ten case study rounds during the term with each student having a writing responsibility in half of them (the student's assignment in the other five rounds is described below). CALVIN automatically assigns a student to a group of four others and to a task within that group. One person in each group is designated the Lead Writer (LW) for that round. The responsibility of the Lead Writer is to prepare an initial draft of the group report which:

- summarizes the major elements of the theory they have been studying;

- analyzes the case from the perspective of that theory.

This draft is 'turned in' electronically and then made available to the other team members and the Instructor.

The other four members of the team function as 'Critics'. Basically the Critics must each tell the Lead Writer in substantive terms how to make the draft document better. In doing so they each prepare a critique of the draft which:

- either certifies that the summary of the theory is satisfactory, or indicates the changes/additions which are needed to make it so;

- indicates in substantive detail what the Lead Writer should do to make the application of the theory stronger.

When each Critic 'turns in' a document, it is automatically made available to the Lead Writer and the Instructor; it also appears on the Critic's own electronic 'grade sheet.' With the critics' suggested improvements in hand the Lead Writer then reworks the initial effort to produce the group report. When the report is submitted via computer to the instructor, it also appears on the grade sheets of each of the five team members.

Normally, since the Lead Writer and Critics share the task in this collaborative fashion, they also share the merit grade their report receives. There are two exceptions to this rule. First, if a member of the group does not meet all the requirements of the assigned role, then that person cannot fully share the group grade. Secondly, owing to the obvious importance of performing one's task in a timely fashion, CALVIN automatically assigns late penalties to individuals who miss the due date for their document. 
During the quarter, each person in the class serves as Lead Writer on one case study and Critic on four others. In addition there is one 'solo' round in which each class member applies a theory to a case as an individual project rather than as a member of a group.

Finally there are the remaining five rounds in which a student has no writing assignment (a Round is constituted by a theory, case study, plus the group roles and their products). Here a student is required to review and grade four reports written by other students. Students receive an evaluation (grade) from the instructor based on how close their review grades are to the scores the instructor assigned the same reports. In the vernacular of the gambling hall the student's grade here is earned by 'betting against the house'. The student thus has less of a workload for this type of assignment, but still carries some responsibility for learning the material.

\section{THE COURSE CONTENT}

The content of the course is rather standard ethical theory as offered in the philosophy departments of universities in the United States and elsewhere. By lecture and assigned readings we first establish an empirical benchmark with Lawrence Kohlberg's and Carol Gilligan's descriptive theories of moral development. We then deal with Individual Ethical Relativism and Cultural Ethical Relativism (always popular positions among undergraduate students, as are Moral Realism and Divine Command Theory which are also covered). Having given the student these polar characterizations of the domain - as well as some basic conceptual equipment/distinctions-we begin our survey of a number of major ethical theories which have enjoyed support in the Western world. Among these are: Utilitarianism, Pragmatism, Existentialism (Kierkegaard, Nietzsche and Sartre) and the theories of Kant, Aristotle, W.D. Ross, Rawls, Hume, E.O. Wilson, A.J. Ayer and G.E. Moore. Most of these theories are used by the students to deal with moral dilemmas in the collaborative, case study format described above.

\section{A sample case study and student response}

Case Study \#8 Berlin, 1943 and the Categorical Imperative

(This case was written by an exchange student from Switzerland who was in the ethical theory course in the spring of 1991)

Helmut started the engine of his locomotive. Steam produced by the boiler pushed the pistons and the train moved slowly. As the speed was increasing Helmut thought, "Maybe I shouldn't do it". But as he was 
throwing coal in the oven of his machine another thought came to his mind, "If I don't do it, someone else is going to do it, and I have a family to feed ..."

"They also say these people are the enemy of the great Germany."

"Anyway, I'm just doing my job and following orders. I'm not responsible."

The train was approaching the railway station. Helmut, preparing for arrival, began bleeding off the engine's steam pressure. As the brakes engaged, he could read the white letters on the station sign indicating the end of the line: AUSCHWITZ.

\section{Case study instructions:}

You are to analyze this case from the perspective of Immanuel Kant's Rational Consistency Theory of morality. First, you need to decide how many arguments run through Helmut's head here. Is each an independent argument, to be considered on its own merits, or is one just a restatement of another? Can each be treated nonconsequentially as Kant would do, or does one or more focus on outcomes?

Next you need to state the fundamental principle or maxim which seems to be embodied in Helmut's statements. It is easy to derail Kant's schema at this point without it receiving a fair test, so to make it work as intended requires a good faith effort to identify the underlying moral issues and state them cleanly.

For each moral issue or argument you have identified what seems to be the result of making its maxim a universal law? Do you get what seems to be any purely logical contradictions? If so, state them. Are there other results of 'scaling up' his maxims which, while undesirable or perhaps unworkable, seem more consequential than logical in nature?

Finally, can Helmut be considered immoral for what he did in terms of Kant's theory? What about the guards on the train? The guards at the prison camp? Those who built the ovens? Those who ran them on a daily basis? The sergeants who gave the guards and workers orders? The lieutenants who gave the sergeants orders? The majors? The colonels? Who? (Remember, this is to be approached in terms of Kant's theory not your own or some other perspective.)

(Note: At this point the roles and responsibilities of the Lead Writer and Critics would be reiterated. These are described above and omitted here to save space.) 
In all the case study rounds half of the class is involved in the collaborative process, as either Lead Writer or Critic, while the other half performs the review function. In each new round the students are randomly assigned. Thus the composition of student groups changes from round to round.

Once the case study assignments for a round have been made, the Lead Writers have two or three days to prepare their draft documents. Should a Lead Writer fail to complete this task on time, the Critics in the group are automatically redistributed to other groups where there is a draft, thus assuring that only the Lead Writer is penalized for missing the due date. Each Critic will have two to three days to provide a substantive critique. The Lead Writer again has two or three days for the final group report. Any tardiness in completing these assignments is penalized on an individual basis.

Once the group reports for a round have been submitted the reviewers (the other half of the class) are then randomly assigned four of these reports to review and grade (also a two or three day task).

After the above tasks have been completed, the instructor reads and grades the group reports. These grades become the 'raw scores' assigned to the members of each group. The instructor may then adjust these 'prima facie' up or down depending on the quality of individual contributions. Individual late penalties are automatically factored in at this time as well. Reviewer grades are also assigned automatically in terms of the difference between the grades the reviewer assigned to each report read and the instructor's 'raw score' grades for these same documents.

Other topics among the forty or so cases we have used in the course are: ethnicity (in connection with cultural ethical relativism), date rape, cheating on 'problem sets' in a computer programming class, a battlefield brutality case used to explore different levels of moral development according to Kohlberg and Gilligan, a utilitarian analysis of playing the lottery, the prima facie and actual duties (Ross' theory) of both a priest and the advertisers of alcohol and tobacco who had flooded his parish with their billboards, gender based career handicaps and 'Aristotelian luck', and a number of cases based on lyrics sung by such popular rock groups as RUSH, Pink Floyd, Twisted Sisters and the 10,000 Maniacs.

\section{THE CALVIN SOFTWARE}

This ethical theory course is supported by what we refer to as CALVIN-The Collaborative Assignment Laboratory: Virtual INteraction system. This courseware enables an instructor to set up and run a 'virtual laboratory' in which students may collaborate on writing assignments. Originally introduced 
in 1991 CALVIN has been an integral part of the learning experience in our course for the past four years. More recently, CALVIN has been used in several other courses at Georgia Tech.

The four basic components of CALVIN are:

- scheduling of assignment tasks (instructor);

- assignment, review, completion and verification (students);

- evaluation and monitoring (instructor);

- miscellaneous correspondence (instructor/students).

Scheduling of Assignment Tasks automatically schedules for each student the correct number of assignments in each category (Lead Writer, Critic, Reviewer) taking into account the constraints outlined previously. In addition CALVIN handles the dynamic rescheduling of individual assignments which is often necessary during the term.

Student Assignment, Review, Completion and Verification embodies student tasks performed on one or the other of four separate display screens:

- the 'In Box';

- the Assignments Screen;

- the Document Editor;

- the Grade Sheet.

The In Box screen is where students learn of their assignments. It is the 'anchor screen' which comes up automatically when the student logs onto the system. There is one line of information for each pending assignment, a line which indicates assignment number, the student's role (lead writer, critique, reviewer, or solo writer), the student's group identifier, if necessary, and the due date.

The Assignment screen contains all the materials necessary to complete an assignment. From here the student can access the case study around which the assignment is built, documents prepared by other members of the group as appropriate and the (initially) blank assignment document where the work is to be done. Should the student delay too long and the due date passes CALVIN offers a reminder of this fact the next time the student logs in.

The Document Editor is a very simple text editor. Alternatively a student may edit a document 'outside' of CALVIN.

Finally the Grade Sheet screen contains a line of identifying information for each completed assignment and the grade it received. From this screen the student can also call up the completed document and see the instructor's comments about its strengths and weaknesses. 
The third component, Evaluation and Monitoring, is an instructor activity accomplished on two main display screens. The first of these is the instructor's 'Evaluation In Box' which provides easy access to whole sets of group documents (draft, critiques, group report) arranged by the round and order submitted. It is at this stage that CALVIN automatically assigns individual late penalties as appropriate and determines reviewer grades.

Student Grade Sheets are available on the instructor's second screen. This screen is also used for periodic monitoring of individual performance and for calculating the course grade at the end of the term.

The fourth component, Miscellaneous Correspondence, is basically an internal version of electronic mail. A 'comforting' feature of CALVIN's email is a '911' system. Students are encouraged to use the 911 option to report emergency situations relating to CALVIN or the course.

\section{UNEXPECTED BENEFITS OF HAVING COMPUTERIZED THE COURSE}

While lacking the resources to seek empirical measures of our success in increasing the student's long term retention of course material, our impressions - as informed by four years of teaching some 3200 students in this mode-are quite positive. Some other positive impressions have emerged as welcome byproducts of the effort.

First, there is the clear, strong impression that the quality of writing in this course is better-much better. Some on-the-surface considerations may account for a part of this perception of marked improvement. First, students write considerably more under the new format. Also, there is less time pressure in the CALVIN assignments. However, student feedback indicates that the major reason for improved writing quality is the concept of peer reviewed work.

Another surprise has been that many students are very positive about the anonymity under which their collaboration takes place. They rarely meet face to face as groups and they do not have any repeated interaction which makes this mode of student collaboration more impersonal than face-to-face discussions. Many students prefer this computer based interaction; especially the quieter, less aggressive ones and those less verbally skilled, perhaps because English is not their first language. And also those whose social confidence is not as great, etc. When they use CALVIN only the quality of your ideas and how clearly you express them count, and you have time to form your thoughts before you must share them. But in face-to-face with a group other things count as well, often too much. Sarcasm, expressions of impatience, feigned boredom, personal 
attacks, glibness, etc., may stifle face to face discussion and cause bad arguments to carry the day.

\section{FUTURE DEVELOPMENT}

A tool such as CALVIN could be beneficial in other collaborative writing settings, particularly those involving large numbers of students and multiple assignments. In addition to the Ethical Theory course CALVIN has been used in other courses taught at Georgia Tech: in the business school, in a second philosophy course and a course in sociology. Our experience indicates that future versions of CALVIN will require more built-in flexibility to allow the instructor to more freely design assignment and group interaction formats. Also we plan to increasingly incorporate multimedia capabilities into the system.

\section{SOME CONCLUDING REMARKS}

- Four years of experience with collaborative, case study based learning built around the CALVIN system affords some tentative lessons about benefits and costs of using computers in ways which depart from the instructional norms of higher education.

- The combination of elements constituting the CALVIN system seem to increase the probability of getting instructional content into the student's long term memory.

- The CALVIN system is successful because it facilitates the model of group interaction: ideas cannot be just memorized, they have to be used to solve problems (the moral dilemmas presented in the cases).

- This teaching/learning model is too complex, especially with regard to scheduling, for it to be used with large classes in a nonautomated environment.

- The main current use of the CALVIN system is for an ethical theory course, but could be adapted easily to other collaborative environments and tasks.

- A substantial reason for CALVIN's acceptance by students lies in the fact that it is easy to learn and use. 